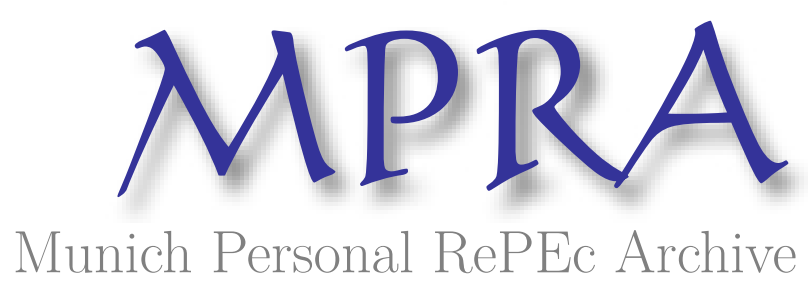

\title{
Interregional migration and thresholds: evidence in Spain
}

Clemente, Jesús and Larramona, Gemma and Olmos, Lorena

University of Zaragoza

2013

Online at https://mpra.ub.uni-muenchen.de/47631/

MPRA Paper No. 47631, posted 17 Jun 2013 19:46 UTC 


\title{
Interregional migration and thresholds: evidence in Spain ${ }^{*}$
}

\author{
Jesús Clemente Gemma Larramona ${ }^{\dagger}$ Lorena Olmos \\ University of Zaragoza
}

\begin{abstract}
The aim of this paper is to analyze the effects of labor market conditions in the origin and the destination on interregional migration in Spain, over the period 1988-2010. A basic theoretical framework is developed and the implications of the model suggest that the effect of labor market conditions on migration can vary, depending on a certain threshold. In a second step, the implications of the model are tested with Spanish data, using a new approach based on the presence of thresholds. We show that interregional migration can be explained by labor market fundamentals if the expected wage gap between the origin and the destination is below an endogenously determinate value.
\end{abstract}

JEL Code: R23, C20, J61

Keywords: Interregional migration, Thresholds, Spain.

\section{Introduction}

The empirical literature on migrations has extensively analyzed the determinants of the emigration decision, with no consensus being reached so far. From a micro-economic perspective, neoclassical theories explain the migration decision through the difference in salaries between the origin and the destination. With this perspective in mind, most papers include salary as an explanatory variable. Moreover, other differences in labor

\footnotetext{
* The authors acknowledge the financial support of the MEC and that of the excellence group ADETRE. The usual disclaimer applies.

${ }^{\dagger}$ Corresponding author. Gran Vía, 2, 50005 Zaragoza, Spain. Phone: +34876554791, email: gemmalar@unizar.es
} 
market conditions, as in the unemployment rate, are also included in order to capture the probability of finding a job, as Harris and Todaro (1970) first considered. Empirical studies commonly conclude that inter-regional migration responds to wages and unemployment. For example, Poncet (2006) finds that migration decisions in China are a response to economic conditions, measured by income and unemployment over time. However, interregional migrations in Spain do not follow this pattern. As Bentolila (2001) highlights, Spanish internal migration flows have been low when compared to other developed European countries, and they do not obviously respond to high unemployment in the regions of residence. Bentolila and Dolado (1991) determine that both real wages and unemployment differences are significant, although they come to this conclusion including several lags and obtain very low elasticities. Jimeno and Bentolila (1998) point out that migration decisions are poorly sensitive to the unemployment rate and real wages. Antolin and Bover (1997) conclude that the unemployment rate has no significant effect on international migration and show that emigration occurs from regions where wages are higher than the average, which seems to contradict many of the theoretical findings. These conflicting conclusions are not only observed for the case of Spain, since Italian internal migrations do not react to mass unemployment, as Fachin (2007) found, nor to an increase in GDP, as determined by Biagi and Faggian (2011).

Figure 1 shows the evolution of gross internal emigration and the unemployment rate, in the extended period 1988-2010, confirming that the lower the unemployment rate in Spain, the higher the interregional gross migration rate. 
Figure 1. Gross interregional migration and unemployment rate, 1988-2010.

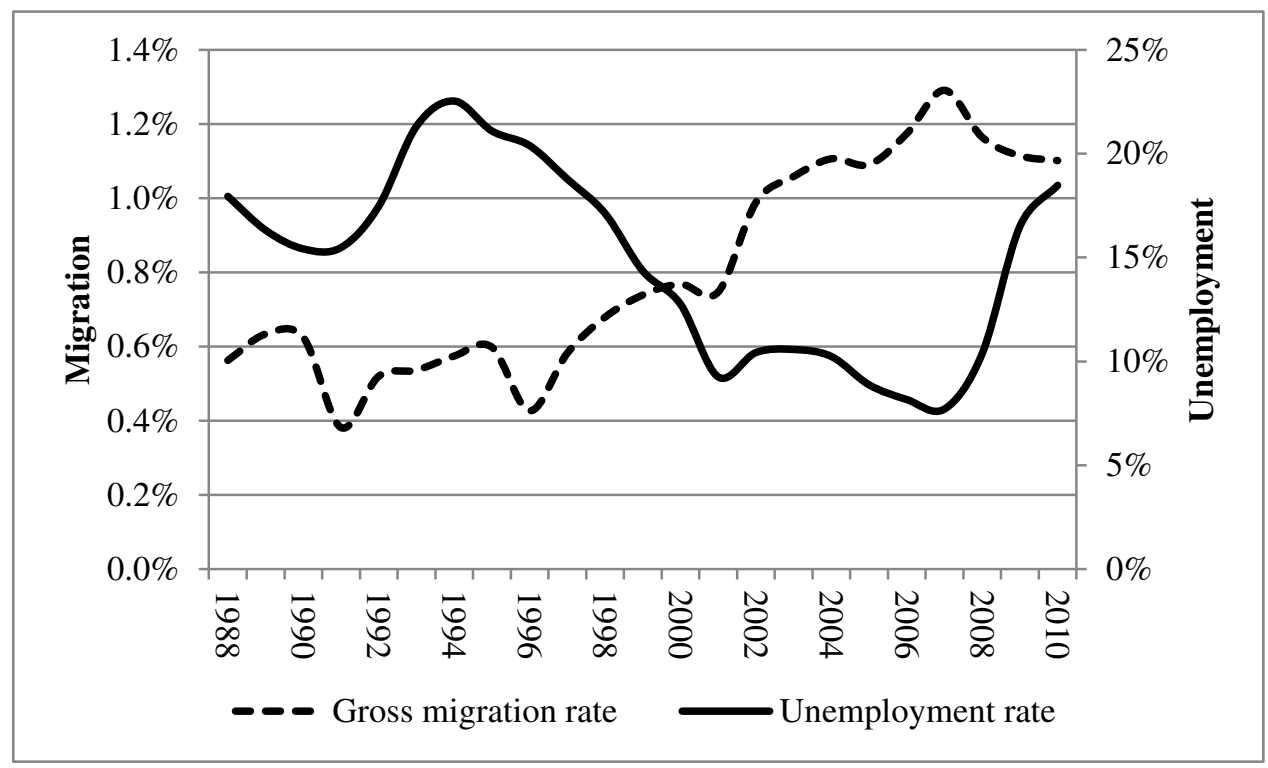

Source: EVR, INE.

These counter-intuitive results, against the hypotheses considered in the majority of theoretical models, have been analyzed with a variety of techniques. Maza and Villaverde (2004), for example, use a semi-parametric model, capturing a weak effect of unemployment rate on internal migration, for the period 1995-2002, while Juarez (2000) considers the inflows and outflows for the period 1962 to 1993, rather than net migration flows. This author analyzes a broad definition of migration, where pull factors of the receiving region and push factors of the origin region are included in the model. Juarez includes a non-linear effect in the unemployment rate and concludes that, under a certain specification, gross migration flows respond with the expected sign to both unemployment rates and wage differentials. Similarly, Muhler and Watson (2010) obtain appropriate signs for the coefficients of unemployment and wages, considering inflows vs. outflows for the period 1990 to 2000, and allowing for the presence of some structural breaks across this sample. These authors demonstrate that the inclusion of housing prices in the empirical study is significant in order to obtain the expected effect 
of unemployment and wages, and they conclude that the effect of labor market variables is different in the period 1990-1995 from the period 1996-2000. However, the period of change is exogenously selected. A structural break has also been considered in other country studies (see Patridge et. al (2012) for counties in the US). These authors also include exogenous thresholds in the size of the counties to answer the lack of migration response to differential economic shocks.

The aim of this paper is to determine the effect of labor market variables on Spanish internal migrations in the period 1988-2010. By extending the Harris and Todaro (1970) model, where expected wage is considered, a simple theoretical framework is developed to demonstrate that, rather than a structural break in a given period, or other exogenously determined thresholds, migration reacts differently depending on the level of the expected wage. This leads us to empirically test the implications of the model. A model with an endogenous method of selection of the threshold value is considered in the econometric specification and, by following Juarez (2000), migration is defined for every region as an outflow from origin region to destination region. Thus, the data indicate the number of outflows from region i to region $\mathrm{j}$. Furthermore, our perspective is that the regional flows are not caused only by labor market variables, since specific regional elements could be key factors in explaining the observed behavior of regional mobility. As the current economic crisis shows, housing prices could be a good proxy of migration costs, and this has been a factor in the migration process.

We show that, when the labor market is characterized by better labor conditions in the destination region, the decision to migrate responds to labor market variables, such as expected wages. By contrast, when the distance between labor market fundamentals is advantageous for the source region, labor market factors are less significant, if at all in the migration decision. 
The paper is organized as follows. Section 2 presents the theoretical model on which we base our empirical exercise. Section 3 presents certain stylized facts and describes the data employed and the econometric methodology. In Section 4, we show the empirical results obtained and, finally, in Section 5, we summarize our main conclusions.

\section{Theoretical model}

Our model consists of an economy with two locations, region of origin $(i)$ and host region $(j)$. Each individual lives one period and, at the beginning of the period, faces the possibility of migrating to another region different from birth region. This decision is taken by comparing the utility derived in both places, $U_{i}$ and $U_{j}$. Thus, the total emigration from the origin region has the following form:

$$
m_{i, j}=f\left(\frac{U_{j}}{U_{i}}\right)
$$

where $\frac{\partial m}{\partial U_{j}}>0$ and $\frac{\partial m}{\partial U_{i}}<0$.

Let us consider an individual deriving utility from goods consumption $c$ and the housing good $h$ in the residence region $r$. In particular, we assume the following utility function, which takes a standard Cobb-Douglas form:

$$
U_{r}=c_{r}^{\propto} h_{r}^{\beta}
$$

with $r=i, j$, and $\propto, \beta>0$. The parameter $\propto$ reflects the elasticity of the consumption good and parameter $\beta$ reflects the elasticity of the housing good.

Each worker contributes to an insurance fund for unemployed workers. Thus, the perceived wage is discounted in the proportion given to non-employed workers, that is, wage multiplied by 1 minus the unemployment rate. 
The budget constraint considers the consumption good price as a constant equal to 1 in the region of birth and the host region. The price of housing, $p$, is a relative price that is not assumed constant and is different in the origin and host region. The positive relationship between housing prices and wages is presented in Carliner (1973), among others. It is assumed that housing prices depend positively on the perceived wage in both the origin and the destination, since housing purchases are not exclusive to residents.

Consequently, the budget constraint is as follows:

$$
c_{r}+p_{r}\left(w_{r}^{e}, w_{-r}^{e}\right) h_{r}=w_{r}^{e}
$$

with $\frac{\partial p_{r}\left(w_{r}^{e}, w_{-r}^{e}\right)}{\partial w_{r}^{e}}>0$ and $\frac{\partial p_{r}\left(w_{r}^{e}, w_{-r}^{e}\right)}{\partial w_{-r}^{e}}>0$, with $r$ and $-r$ being residential and nonresidential areas respectively, and $w_{r}^{e}$ the expected wage in each area (that is, the wage weighted by the unemployment rate).

Solving the problem of maximizing equation (1) subject to the budget constraint (2), the optimal consumption and housing goods are characterized by the following values, respectively:

$$
\begin{aligned}
& c_{r}=\frac{\alpha w_{r}^{e}}{\propto+\beta} \\
& h_{r}=\frac{\beta w_{r}^{e}}{(\alpha+\beta) p_{r}\left(w_{r}^{e}, w_{-r}^{e}\right)}
\end{aligned}
$$

From equations (3) and (4) it is straightforward to check that a higher expected wage in the origin region increases the purchase of consumption goods, but the effect is indeterminate in the case of the purchase-of-housing good. 
The effect of an increase of the expected wage in region $-r$ is negative in the utility of region $r$, and the effect of an increase in the expected wage in region $r$ on the utility of region $r$ is also negative, if

$$
\frac{w_{r}^{e}}{p_{r}\left(w_{r}^{e}, w_{-r}^{e}\right)} \frac{\partial p_{r}\left(w_{r}^{e}, w_{-r}^{e}\right)}{\partial w_{r}^{e}}>\frac{\alpha+\beta}{\alpha}
$$

In other words, if the elasticity of housing price to expected wage is sufficiently high (higher than 1), which occurs with goods considered luxury goods, the effect of an increase in wages could increase the housing price to the extent that the utility of the region could decrease.

Inequality (5) will be true, the greater are the expected wages in the residence region, in this case, migration does not react conventionally to an increase in the expected wage. If equation (5) is valid, an increase in the income perceived in the region of origin could act as a push factor for emigration.

In sum, when the labor market is characterized by low expected wages in the origin region, the migration decision responds to labor market variables. By contrast, when labor market conditions in the origin are sufficiently good, labor market factors are less significant, and could even react contrary to the results derived from neoclassical migration models. Our model also emphasizes that other institutional factors, such as housing prices, are also explanatory elements.

\section{Data and Empirical Methodology}

The statistical sources of our annual frequency database, which covers the period 19882010 for the 17 Spanish regions (Autonomous Communities), are captured from different databases. The data of the unemployment rate and the labor force of each region has been obtained from the working population survey (Encuesta de Población 
Activa, EPA) provided by the Spanish National Statistics Institute (Instituto Nacional de Estadística, INE). Nominal wages are calculated by dividing total employee earnings by the number of employed workers, both series obtained from the Statistics of the Spanish Ministry of Economy and Competiveness. This data has been deflated by the CPI index to obtain real wages. Housing price data is provided by the Spanish real estate valuation society "Sociedad de Tasación", the only source of information that covers the analyzed period and disaggregates across regions. Finally, geographical distance is measured in kilometers between the capitals of each region. The series that have a higher frequency have been annualized by taking the annual average value.

A first approach to the data shows a non-conventional influence of certain labor market conditions on migration rates in Spain. The first difference is the counter-intuitive evolution of the variables unemployment and migration, presented in Figure 1. This result indicates that unemployment considered in isolation could be a non-appropriate explanatory variable for migration. The expected wage, which is the real wage multiplied by 1 minus the unemployment rate, can be an improved measure of labor market conditions since it takes into account both the potential wage earnings and the probability of finding a job. Despite the fact that expected wages have been considered in many theoretical papers analyzing migrations, empirical papers do not normally capture this. Figure 2 shows the scatter plot of the relative expected wage of the region over the mean of the whole of Spain in the horizontal axis, and the net migration rate on the vertical axis, defined as inflows less outflows over population, for every region and for every year. Net migration rate is used, rather than gross migration rate, in this first step, since an aggregate measure is required for the descriptive statistics. 
Figure 2: Interregional net migration rate and relative expected wage, 1988-2010.

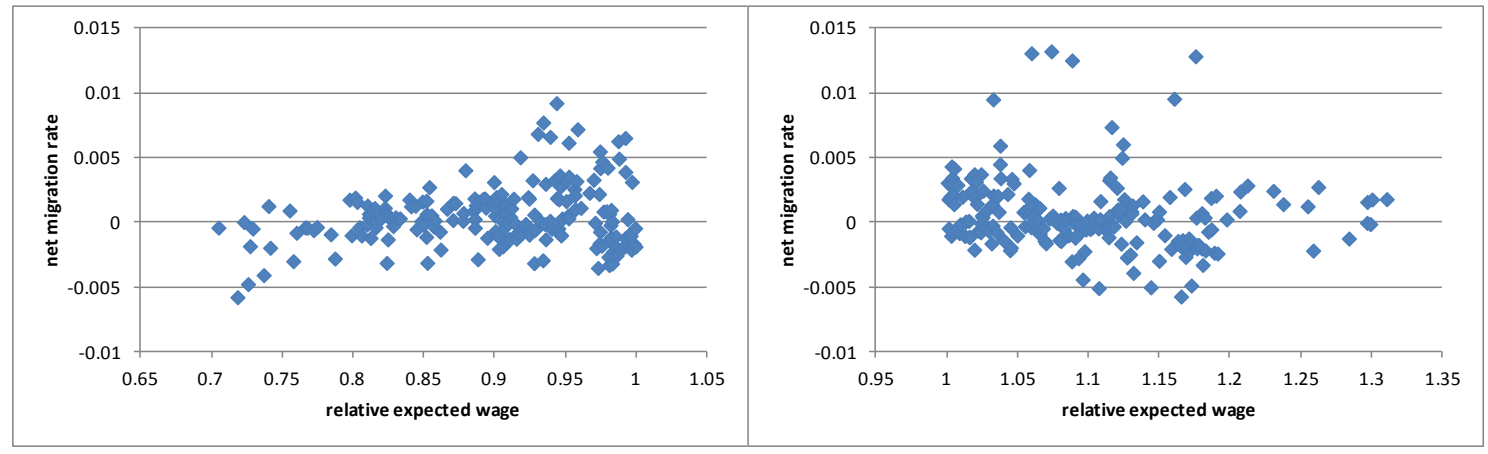

Source: EVR, INE.

Figure 2 shows a different pattern in the relationship between net migration rate and the relative expected wage for relative expected wages under and over 1 . On the left of Figure 2, the relative expected wage below 1 is presented, showing a positive relationship between net migration rate and relative expected wage. This is the result predicted by theory, the greater the expected wage in the origin over the mean of the country as a whole, the greater will be inflows over outflows. On the right of Figure 2, the relative expected wage above 1 is presented, and the relationship to migration is not so clear. A relative expected ratio over 1 would suggest positive and increasing values of the net migration rate, and this pattern does not appear. The reason for this could be the use of aggregate measures where it is impossible to determine if the outflows go to regions with higher expected wages, higher than the mean of the country as a whole, or not, which encourages the use of a database where detailed information on origin and destination variables is provided. Other reasons could be the presence of thresholds, that is, different relationships depending on the level of expected wages, or the effect of other variables, such as housing prices, as the basic model highlights. In fact, Figure 3 shows the scatter plot of the housing price in the horizontal axis and the net migration rate on the vertical axis, illustrating a negative relationship between both variables. The higher the prices in the origin region, the lower the inflows over outflows. 
Figure 3: Interregional net migration rate and housing prices, 1988-2010.

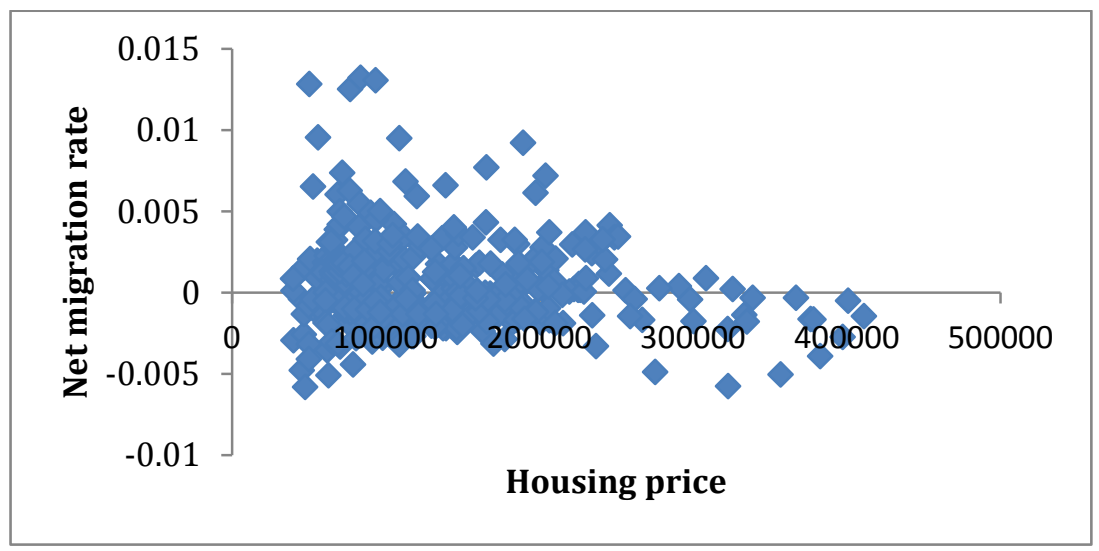

Source: EVR, INE and Sociedad de Tasación.

Our estimation procedure has two steps. First, a simple regression with real wages and unemployment as independent variables is made to justify the utility of including the aggregate variable expected wages with the detailed dataset. Apart from using labor market conditions and housing prices to explain migrations, certain other variables have been considered. Based on the gravity equation that has been applied to the study of migration flows (see Greenwood, 1975, or more recently an extended gravity model used in Etzo, 2011), migrants make their decisions according to two sets of variables: the attractive forces of the destination, and the costs of migration. If the expected value of the first factors, where we can include economic, social or institutional factors, outweighs the latter, the migration will take place.

Assuming, as usual in the related literature, that the labor force size in the origin and in the destination contributes positively to migration, we will consider as attractive forces higher expected wage in the target region and lower housing prices in the origin region. The costs of moving from the origin to the destination would be the distance between regions, which is also a proxy of other costs of migration, housing prices in the receiver 
region, and lower expected real wages in the origin. Against this background, we can initially propose Model I:

$$
\begin{aligned}
\ln M_{i j, t}=\beta_{0}+ & \beta_{1} \ln n_{i, t}+\beta_{2} \ln n_{j, t}+\beta_{3} \ln h_{i, t}+\beta_{4} \ln h_{j, t}+\beta_{5} u_{i}+\beta_{6} u_{j} \\
& +\beta_{7} \ln w_{\mathrm{i}, \mathrm{t}}+\beta_{8} \ln \mathrm{w}_{\mathrm{j}, \mathrm{t}}+\beta_{9} \ln d_{i j}+\beta_{10} \text { origin }+\varepsilon_{i j, t}
\end{aligned}
$$

In this specification, $M_{i j}$ represents the migration flow, that is, the number of those who migrate from region $i$ to region $j, n$ is the labor force, $h$ is the housing price, $u$ is the unemployment rate, $w$ is the real wage, $d_{i j}$ is the geographic distance between region $i$ and $j$, and $\varepsilon_{t}$ represents the perturbation of the model. We have additionally included 16 dummy variables to capture the idiosyncratic effect of each of the source regions, which take value 1 for the origin region and 0 otherwise. For the sake of brevity, we will not include other kinds of fixed effects as dummies for the destination region or year.

To test whether the model specification is improved when the expected wage variable is introduced, rather than unemployment and wages separately, we propose Model II:

$$
\begin{aligned}
\ln M_{i j, t}=\beta_{0}+ & \beta_{1} \ln n_{i, t}+\beta_{2} \ln n_{j, t}+\beta_{3} \ln h_{i, t}+\beta_{4} \ln h_{j, t}+\beta_{5} \ln w_{i, t}^{e}+\beta_{6} \ln w_{j, t}^{e} \\
& +\beta_{7} \ln d_{i j}+\beta_{8} \text { origin }+\varepsilon_{i j, t}
\end{aligned}
$$

where $w_{i j, t}^{e}=w_{i j, t}\left(1-u_{i j, t}\right)$ is the expected real wage.

It would seem reasonable that, when the relative opportunities in the labor market of the destination region are higher, the decisions of migrants fit traditional patterns while, if the economic gain of moving is relatively low, migrants pay attention to other factors, making the labor market variables less decisive. Thus, the model can be nonlinear. In order to capture this nonlinearity, in a second step a model with an endogenous method of selection of the thresholds is considered, and we specify Model III:

$$
\ln \left(M_{i j, t}\right)=z_{i j, t} \delta_{1}+\Gamma_{i j, t} \Phi+\epsilon_{1, i j, t} \quad \text { if } \quad q_{i j, t} \leq \gamma
$$




$$
\ln \left(M_{i j, t}\right)=z_{i j, t} \delta_{2}+\Gamma_{i j, t} \Phi+\epsilon_{2, i j, t} \text { if } \quad q_{i j, t}>\gamma
$$

where $z_{i j, t}=\left[1, \ln \left(n_{i, t}, n_{j, t}, h_{i, t}, h_{j, t}, w_{i, t}^{e}, w_{j, t}^{e}, d_{i j}\right)\right], 1$ reflects the intercept, $\delta_{1}$ and $\delta_{2}$ are two vectors of parameters, $\Gamma_{i j, t}$ is a matrix that includes the dummy variables, $\Phi$ is a vector of parameters, and $q_{i j, t}$ is the threshold variable. If the parameter $\gamma$ were known, we could easily test for the linearity null hypothesis and estimate the system. However, this parameter is unknown and, consequently, we should first carry out an estimate. To do this, we perform a grid search, using a $15 \%$ trimming. The estimated value of the parameter $\gamma$ coincides with the value that maximizes the LM statistic for testing the $\delta_{1}=\delta_{2}$ null hypothesis.

\section{Results}

In this Section, we detail our econometric outcome. We show the results of the estimation of Models I and II without thresholds in Table 1, and Model III in Table 2, in which we present the elasticity coefficients of each variable. We should note that the tratios are corrected by the White statistic, taking into account the presence of heteroscedasticity.

In Model I in Table 1, the unemployment rate in the origin is not significant in explaining interregional migrations in Spain, and the unemployment rate in the host region has the opposite sign; that is, if the unemployment rate at the destination increases by $1 \%$, the immigration to this region will increase by $0.07 \%$. This has been corrected in Model II by introducing expected wages as an aggregate variable, and all signs obtained are as expected. The total working population in both origin and destination regions positively affects the migration flow. Housing prices in the source region also have a positive relationship with migration flow, since migrants try to 
minimize that cost. By contrast, higher housing prices in the destination region discourage the migration decision. Finally, geographic distance negatively influences migration flows. Model II leads us to conclude that a $1 \%$ of increase in the expected wage at the origin decreases emigration from this region by $0.23 \%$, while the pull factor of the host region is greater, $0.39 \%$.

Following the results derived in the theoretical framework, a threshold in expected wages is considered, but as this variable is built with regional wages and unemployment rates, both variables are considered separately as thresholds. Thus, we consider three labor market gaps as threshold variables in order to consider other alternatives.

Regarding Model III, shown in Table 2, the upper part corresponds to the estimation of the value of threshold $\gamma$, the value of the statistic that test for the null hypothesis of no presence of threshold, and the joint model $\mathrm{R}^{2}$, while the second and third parts exhibit the elasticities of the different models for $q_{i j, t} \leq \gamma$ and $q_{i j, t}>\gamma$, respectively.

We estimate $\gamma$ and then test the null hypothesis of no presence of threshold. To test for the non-linearity hypothesis, we have calculated the critical values of the distribution by way of bootstrap techniques. In order to ensure that the critical values provide sufficient reliability, we have conducted 500 replications, obtaining the critical values shown in Table 3. Thus, in all cases, we can reject the null linearity hypothesis, and we confirm the existence of different behaviors depending on the value taken by the threshold variable considered.

We begin by considering the case of the unemployment rate as the threshold variable. The first column of Table 2 shows that migration behavior has two parts, that is, for smaller and larger values of $u_{i} / u_{j}=0.81$, and all the coefficients have the expected sign. When the unemployment rate in the source region is lower by a certain proportion than 
the rate in the target region, the significance of the size of the labor force in both regions is lower. The expected real wage in both regions is not significant, so we conclude that labor factors are not decisive when labor market conditions are favorable in the origin region. Moreover, housing prices in both regions are significant and the geographical distance has little influence.

We now analyze the estimation of the model when we allow for thresholds depending on the real wage gap. We should note that the interpretation in this case is contrary, because the sub-sample for $q_{i j, t} \leq \gamma$ refers to less favorable labor conditions in the origin region. The value of the threshold for which migration movements change the response to the explanatory variables is 0.921 . In this case, all the variables included are more significant when the labor conditions are not favorable to the origin region and the power of explanation of the model is slightly higher. In fact, expected real wages are not significant, or close to zero, when labor conditions are advantageous.

Finally, the gap in expected real wages as a threshold variable is considered. This case is similar to the previous one in terms of interpretation, with a very close threshold value. The size of the labor force of both regions is more of a determinant when the expected wage at the origin is less than $92 \%$ of the expected wage in the host region, and the coefficient of explanation is higher. The same happens with housing prices and distance. The greatest difference is that the influence of labor market conditions in origin or destination is less important when the expected wage at the origin is sufficiently high. In this case, and as the theoretical model shows, the effect of the expected wage in the origin region is significant and positive, indicating that an increase of the expected wage in the origin region increases the outflow of migrants to other regions. From Table 2, it can also be concluded that the push factors of the origin region have a greater effect on migration than the pull factors of the host regions. 
The global interpretation of Table 2 shows some interesting results that can be helpful in understanding migration flows in Spain. The estimated coefficients indicate that the influence of the determinants can differ, depending on the absolute value of the labor market conditions. Thus, distance is more important when the conditions of the origin region are worse, better labor conditions at the origin lead migrants to place less weight on the associated costs of moving. The same effect is detected when the housing price is analyzed. The results can be affected by the subjective perception of the risk; that it is to say, a low wage means that the percentage of income used for the mortgage payment is greater and consequently the migration cost is perceived as being more important.

Finally, as the theoretical model states, the expected wage in the origin and at the destination has a greater effect on migrations when economic conditions in the origin region are relatively worse.

\section{Conclusions}

In this paper we have analyzed inter-regional migrations in Spain during the period 1988-2010, considering origin and destination labor market conditions. A simple theoretical model is developed to capture the idea that migration reacts differently to different levels of expected wages, rather than to structural breaks or exogenously determined thresholds. The main implications of the model are tested empirically. Our perspective is innovative, since potential wage is considered as a key variable and nonlinearities in migration flows are allowed by including thresholds in labor market conditions. Our results indicate that, when labor market conditions are unfavorable in the origin region, migrants make their decisions based on the labor market conditions and housing prices in both origin and destination, as well as on the distance between the regions. All the variables have a high capacity of explanation, with those that capture 
the push factors, rather than the pull factors, being greater. However, when relative labor market conditions in the source region are good enough, migration flows are less responsive, or even indifferent, to expected wages, suggesting that migrants are less sensitive to labor variables. 


\section{References}

Antolin, P. and Bover, O. (1997) "Regional Migration in Spain: The Effect of Personal

Characteristics and of Unemployment, Wage and of Housing Price Differentials Using Pooled Cross-Sections," Oxford Bulletin of Economics and Statistics, 59.2.

Bentolila, S. and Dolado, J.J. (1991) "Mismatch and Internal Migration in Spain,” in F.Padoa-Schioppa, ed, Mismatch and Labor Mobility, Cambridge University Press.

Bentolila, S. (2001) "Las migraciones interiores en España," Documento de trabajo FEDEA n ${ }^{\circ}$ 2001-07.

Biagi, B. and Faggian, A. (2011) "Long and short distance migration in Italy: The role of economic, social and environmental characteristics," Spatial Economic Analysis, 6, pp.111-130.

Carliner, G. (1973): "Income elasticity of housing demand," The Review of Economics and Statistics, 55, pp. 528-532.

Etzo, I. (2011) “The determinants of the recent interregional migration flows in Italy: A panel data analysis," Journal of Regional Science, 51, pp.948-966.

Fachin, S. (2007) "Long-run trends in internal migrations in Italy: a study in panel cointegration with dependent units," Journal of Applied Econometrics, 222, pp. 401428.

Greenwood, M. (1975) "Research on Internal Migration in the United States: a Survey," Journal of Economic Literature, 13, pp. 397-433.

Harris, J. and Todaro, M. (1970) "Migration, Unemployment and Development: A Two- Sector Analysis," American Economic Review, 60, pp. 126-142. 
Jimeno-Serrano J.F. and Bentolila, S. (1998) "Regional Unemployment Persistence (Spain 1976-94)," Labor Economics, 5, pp. 25-51.

Juarez, J. P. (2000): “Analysis of Interregional Labor Migration in Spain Using Gross Flows," Journal of Regional Science, 40, pp. 377-399.

Maza, A. and Villaverde, J. (2004) “Interregional Migration in Spain: A Semiparametric Analysis," The Review of Regional Studies, 34, pp. 37-52.

Mulhern, A. and Watson, J. (2012) "Spanish Inter-Regional Migration: an Enigma Resolved," Applied Economics Letters, 17, pp. 1355-1359.

Patridge, M., Rickman, D., Olfert, M and Ali, K. (2012) "Dwindling U.S. internal migration: Evidence of spatial equilibrium or structural shifts in local labor markets?," Regional Science and Urban Economics, 42, pp. 375-388.

Poncet, S. (2006) "Provincial migration dynamics in China: Borders, costs and economic motivations," Regional Science and Urban Economics, 36, pp. 385-398. 
Table 1: Models without Thresholds

\begin{tabular}{c|cc}
\hline \hline & Model I & Model II \\
\cline { 2 - 3 } Intercept & $-5.99^{\mathrm{a}}$ & $-4.07^{\mathrm{a}}$ \\
Labor force $_{\mathrm{i}}$ & $1.30^{\mathrm{a}}$ & $1.19^{\mathrm{a}}$ \\
Labor force $_{\mathrm{j}}$ & $0.94^{\mathrm{a}}$ & $0.94^{\mathrm{a}}$ \\
Housing price $_{\mathrm{i}}$ & $0.51^{\mathrm{a}}$ & $0.36^{\mathrm{a}}$ \\
Housing price $_{\mathrm{j}}$ & $-0.53^{\mathrm{a}}$ & $-0.41^{\mathrm{a}}$ \\
Unemployment $_{\mathrm{i}}$ & 0.06 & \\
Unemployment $_{\mathrm{j}}$ & $0.07^{\mathrm{a}}$ & \\
Wage $_{\mathrm{i}}$ & $-0.81^{\mathrm{a}}$ & \\
Wage $_{\mathrm{j}}$ & $1.06^{\mathrm{a}}$ & \\
Expected wage $_{\mathrm{i}}$ & & $-0.23^{\mathrm{a}}$ \\
Expected wage $_{\mathrm{j}}$ & & $0.39^{\mathrm{a}}$ \\
Distance $_{\mathrm{ij}}$ & $-0.65^{\mathrm{a}}$ & $-0.63^{\mathrm{a}}$ \\
Origin Dummies $^{2}$ & Yes $^{2}$ & Yes \\
$\mathrm{R}^{2}$ & 0.83 & 0.83 \\
Observations $^{2}$ & 6256 & 6256 \\
\hline \hline
\end{tabular}

a,b denote significance at $5 \%$ and $10 \%$, respectively. 
Table 2: Model III with thresholds

\begin{tabular}{|c|c|c|c|}
\hline \multicolumn{2}{|r|}{$q: u_{i} / u_{j}$} & $q: w_{i} / w_{j}$ & $\bar{q}: w_{i, t}^{e} / w_{i, t}^{e}$ \\
\hline$q^{*}$ & 0.813 & 0.921 & 0.92 \\
\hline LM Test & 237.99 & 200.75 & 216.25 \\
\hline $\mathrm{R}^{2}$ & 0.83 & 0.83 & 0.83 \\
\hline \multicolumn{4}{|c|}{$q<q^{*}$} \\
\hline Intercept & $-4.93^{\mathrm{a}}$ & $-1.94^{\mathrm{a}}$ & $-1.88^{\mathrm{a}}$ \\
\hline Labor force $_{i}$ & $0.79^{\mathrm{a}}$ & $1.75^{\mathrm{a}}$ & $1.81^{\mathrm{a}}$ \\
\hline Labor force $_{j}$ & $0.93^{\mathrm{a}}$ & $1.12^{\mathrm{a}}$ & $1.18^{\mathrm{a}}$ \\
\hline Housing price $_{i}$ & $0.59^{\mathrm{a}}$ & $0.44^{\mathrm{a}}$ & $0.77^{\mathrm{a}}$ \\
\hline Housing price $_{j}$ & $-0.31^{\mathrm{a}}$ & $-0.89^{a}$ & $-1.02^{\mathrm{a}}$ \\
\hline Expected wage $_{\mathrm{i}}$ & -0.45 & $-0.76^{\mathrm{b}}$ & $-1.06^{\mathrm{a}}$ \\
\hline Expected wage $_{j}$ & $0.36^{\mathrm{b}}$ & $0.90^{\mathrm{a}}$ & $0.83^{\mathrm{a}}$ \\
\hline Distance $_{i j}$ & $-0.38^{\mathrm{a}}$ & $-0.73^{\mathrm{a}}$ & $-0.61^{\mathrm{a}}$ \\
\hline Origin Dummies & Yes & Yes & Yes \\
\hline Observations & 1952 & 2150 & 1734 \\
\hline $\mathrm{R}^{2}$ & 0.84 & 0.83 & 0.84 \\
\hline \multicolumn{4}{|c|}{$q>q^{*}$} \\
\hline Intercept & -2.67 & $-5.43^{\mathrm{a}}$ & $-5.75^{\mathrm{a}}$ \\
\hline Labor force $_{i}$ & $1.40^{\mathrm{a}}$ & $0.99^{\mathrm{a}}$ & $1.05^{\mathrm{a}}$ \\
\hline Labor force $_{j}$ & $0.97^{\mathrm{a}}$ & $0.86^{\mathrm{a}}$ & $0.87^{\mathrm{a}}$ \\
\hline Housing price $_{i}$ & 0.22 & 0.44 & 0.25 \\
\hline Housing price $_{j}$ & $-0.51^{\mathrm{a}}$ & $-0.35^{\mathrm{a}}$ & $-0.34^{\mathrm{a}}$ \\
\hline Expected wage $_{i}$ & $-0.31^{\mathrm{a}}$ & $0.007^{\mathrm{a}}$ & $0.19^{\mathrm{a}}$ \\
\hline Expected wage $_{j}$ & $0.60^{\mathrm{a}}$ & $0.23^{\mathrm{b}}$ & $0.25^{\mathrm{a}}$ \\
\hline Distance $_{i j}$ & $-0.77^{\mathrm{a}}$ & $-0.56^{\mathrm{a}}$ & $-0.60^{\mathrm{a}}$ \\
\hline Origin Dummies & Yes & Yes & Yes \\
\hline Observations & 4304 & 4106 & 4522 \\
\hline $\mathrm{R}^{2}$ & 0.71 & 0.81 & 0.73 \\
\hline
\end{tabular}

a,b denote significance at $5 \%$ and $10 \%$, respectively.

Table 3: Bootstrap Results

\begin{tabular}{c|ccc}
\hline \hline Significance Level & $q: u_{i} / u_{j}$ & $q: w_{i} / w_{j}$ & $q: w_{i, t}^{e} / w_{j, t}^{e}$ \\
\hline $1 \%$ & 27.12 & 26.75 & 25.30 \\
$5 \%$ & 24.36 & 23.45 & 21.14 \\
$10 \%$ & 21.80 & 20.63 & 18.87 \\
\hline \hline
\end{tabular}

